\title{
CORRELATION BETWEEN CALCANEAL BONE ULTRASOUND MEASUREMENTS AND DENSITOMETRY AMONG POSTMENOPAUSAL WOMEN WITH FRACTURES CAUSED BY BONE FRAGILITY
}

Frederico Barra Moraes ${ }^{1}$, Lindomar Guimarães de Oliveira², Pierre de Souza Novais ${ }^{3}$, Murilo Rodrigues Melo ${ }^{3}$, Mara Lúcia Rassi Guimarães ${ }^{4}$

\begin{abstract}
Objective: To assess the correlation between ultrasound (US) measurement on the calcaneus and bone densitometry (DEXA), among postmenopausal women who already presented fragility fractures. Methods: 35 postmenopausal women over 40 years of age, with the ability to walk and presenting osteoporotic fractures of the wrist or spine, without previous treatment for osteoporosis, were analyzed in a retrospective cohort. Of these, 16 were under 60 and 19 were over 60 . The broadband ultrasound attenuation (BUA) and speed of sound (SOS) were compared using DEXA (L1-L4, total femur, femoral neck and wrist). Two different values of BUA were used as cutoff points for osteoporosis: BUA $<60 \mathrm{~dB} / \mathrm{MHz}$ and BUA $<64 \mathrm{~dB} / \mathrm{MHz}(\mathrm{P}<0.05)$; and SOS $<1600 \mathrm{~m} / \mathrm{s}$. The confidence interval was $95 \%$. The DEXA and US data were plotted on dispersion graphs
\end{abstract}

and, through linear regression, it was possible to establish correlations. Following this, the sample was stratified according to age (up to 60 years and 60 years and over). Thus, the values were again compared and correlated. Results: The best correlation obtained between DEXA and US was between the T-score of the wrist and BUA $<64 \mathrm{~dB} / \mathrm{MHz}$, with $92 \%$ sensitivity and $95 \%$ specificity. Better sensitivity at all DEXA sites was obtained when US was performed on patients over 60 years of age. The SOS compatible with osteoporosis was $<1592.5 \mathrm{~m} / \mathrm{s}$ ( $89 \%$ sensitivity and $85 \%$ specificity). Conclusion: US on the calcaneus can be used for screening the risk of osteoporosis fractures, using a cutoff of BUA $<64 \mathrm{~dB} /$ $\mathrm{MHz}$, especially among patients over 60 years of age.

Keywords - Calcaneus; Ultrasound; Bone Density; Postmenopausal Osteoporosis/prevention and control

\section{INTRODUCTION}

Osteoporosis is a systemic disease which is characterized by low bone mass and a deterioration in the bone microarchitecture, leading to a decrease in its biomechanical resistance, which, in turn, creates a relatively higher (2-4 times) risk of fractures ${ }^{(1)}$.

It presents important prevalence in the worldwide population, affecting 30 out of 100 post-menopausal women. Another important factor is that the population is ageing due to a longer life expectancy, which also increases the number of fractures caused by osteoporosis. In 2000, Brazil had more than 14,000,000 people aged over 60 years $^{(2)}$.

Despite the medical treatments available to treat patients with osteoporosis and reduce the risk of fractures, many patients are asymptomatic, not diagnosed

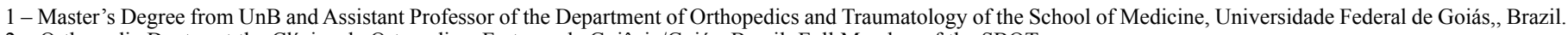

2 - Orthopedic Doctor at the Clínica de Ortopedia e Fraturas de Goiânia/Goiás, Brazil; Full Member of the SBOT.

3 - Trainee of the Trauma League of the Department of Orthopedics and Traumatology of the School of Medicine, Universidade Federal de Goiás, Brazil.

4 - Resident Doctor in Physiatry of the Centro de Reabilitação Dr. Henrique Santillo, Goiânia/Goiás, Brazil. 
or undertreated ${ }^{(3-6)}$. Ideally, to avoid fractures, osteoporosis should be diagnosed early, which is currently done by bone density scan (DEXA). Bone ultrasound has been performed as a method of screening the population, to evaluate the risk of fracture ${ }^{(7)}$; however, there is still controversy on the usefulness of this method, as there are few studies that demonstrate the ideal values for correlation of BUA and SOS with $\operatorname{DEXA}^{(8)}$.

Prospective studies have shown that ultrasound of the calcaneus can predict a risk of bone fracture, as well as $\operatorname{DEXA}^{(9,10)}$. The method also presents several advantages: it is cheaper, portable, and does not involve ionizing radiation ${ }^{(11)}$.

The objective of this work is to evaluate the correlation between ultrasound of the calcaneus and DEXA in post-menopausal women, in the city of Goiânia, Goiás, who already presented a fracture due to osteoporosis.

\section{METHOD}

A retrospective cohort study was carried out involving 35 women with osteoporotic fractures of the wrist or vertebral spine, who were able to walk, aged over 40 years, post-menopausal, attending the Orthopedics and Fracture Clinic, and without prior treatment for osteoporosis. Of these patients, 15 presented fracture of the vertebral column and 20, fracture of the wrist. All were submitted to non-surgical treatment. Of these women, 16 were aged below 60 years, and 19 were 60 or over (from 44 to 87 , with a mean age of 61.6 years).

BUA and SOS were correlated in dispersion graphs, with the DEXA sites (L1-L4, total femur, neck of the femur, right wrist and left wrist), both in the general population and in stratified population (aged under 60 and 60 or over). The equation was then calculated for linear regression and the strength of correlation between the variables through Pearson's correlation.

To predict the risk of osteoporotic fracture, BUA $<60 \mathrm{~dB} / \mathrm{MHz}$ was initially adopted, and then BUA $<$ $64 \mathrm{~dB} / \mathrm{MHz}^{(8)}$.

As for SOS, the value that predicts the risk factor was calculated by the linear regression equation.

A confidence interval of $95 \%$ was adopted, with $p$ $<0.05$ considered significant.
Ultrasound was carried out with the SONOST-2000 device and DEXA with a Lunar device. The research was carried out in the COF - Orthopedics and Fracture Clinic of Goiânia, Goiás, and authorized by the ethics committee of the COF.

\section{RESULTS}

The results are shown in Figures 1, 2, 3 and 4 and in Tables 1, 2 and 3 below.

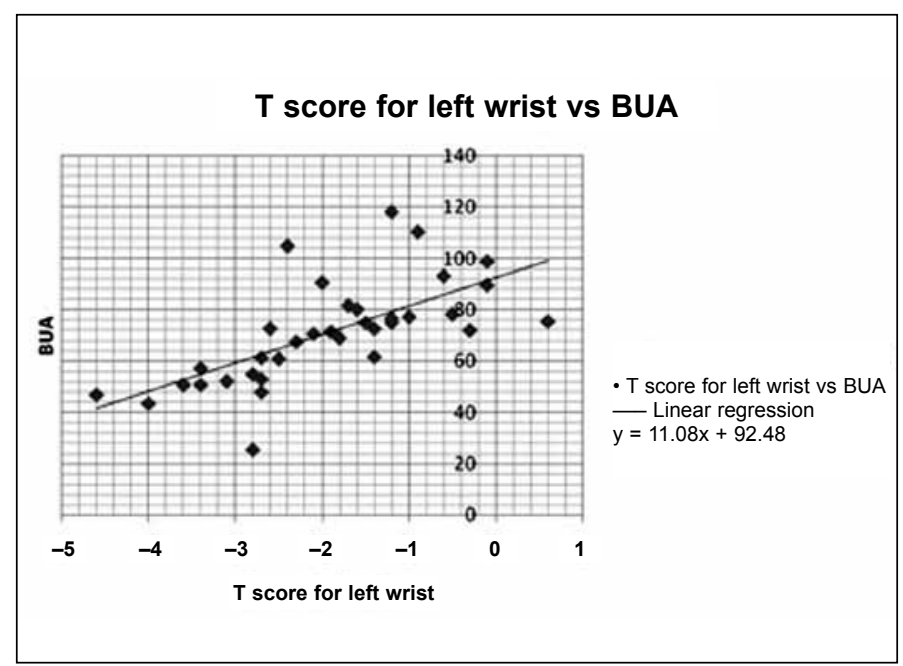

Figure 1 - Association between BUA and T score of the wrist for all the patients in the sample. Adopting a value for BUA < $60 \mathrm{~dB} / \mathrm{MHz}$, sensitivity of $77 \%$, specificity of $100 \%$ and positive predictive value of $100 \%$ were obtained. When BUA $<64 \mathrm{~dB} / \mathrm{MHz}$ was adopted, the sensitivity obtained was $92 \%$, with specificity of $95 \%$ and a positive predictive value of $92 \%$.

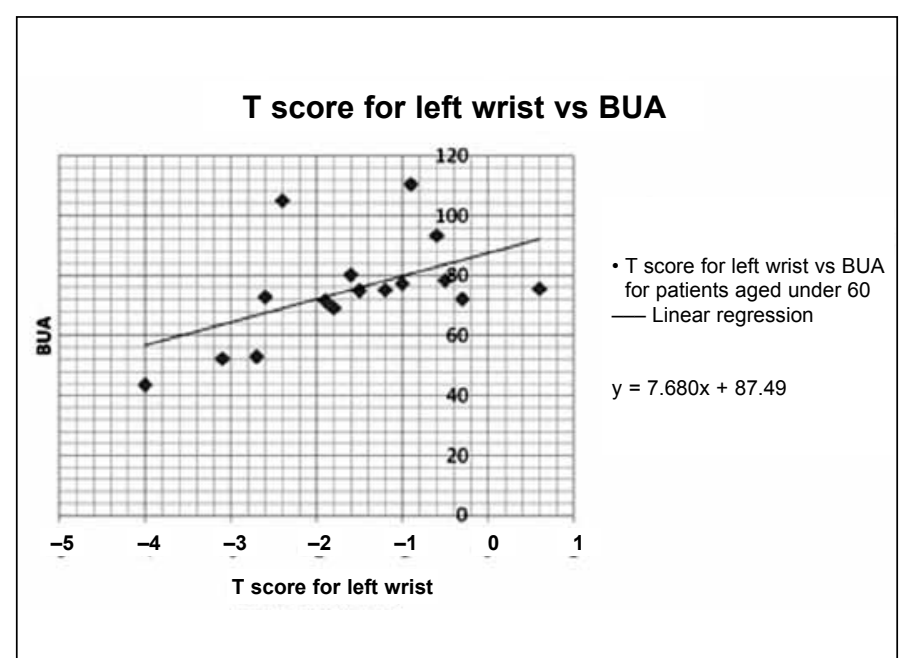

Figure 2 - Association between BUA and T score of the wrist by DEXA in patients aged under 60 . Using a value for $B U A<60 \mathrm{~dB} /$ $\mathrm{MHz}$, sensitivity of $75 \%$, specificity of $100 \%$ and positive predictive value of $100 \%$ were obtained. Using $\mathrm{BUA}<64 \mathrm{~dB} / \mathrm{MHz}$, no alterations in sensitivity, specificity and positive predictive value were obtained, compared with the values above. 


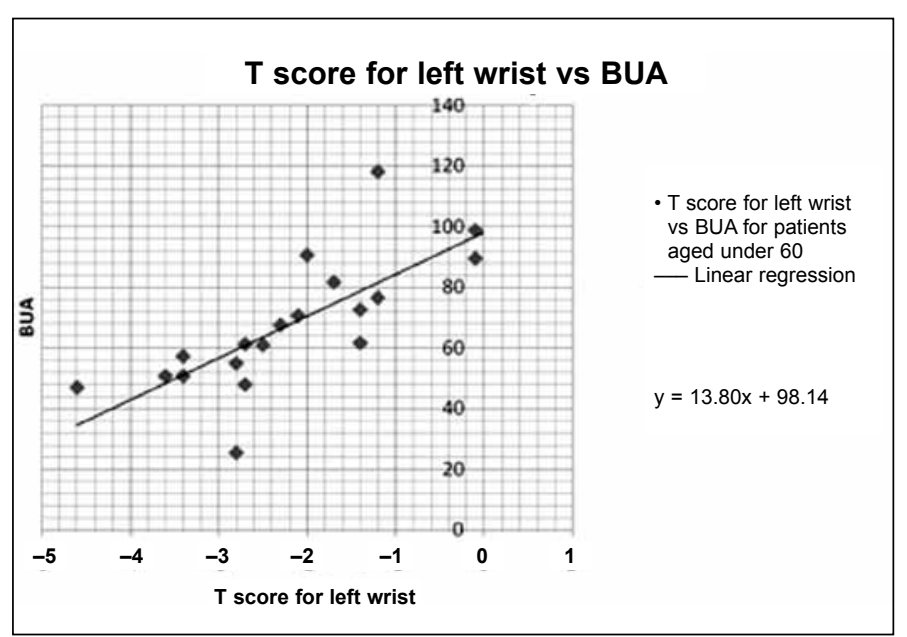

Figure 3 - Association between BUA and T score of the wrist by DEXA in patients aged over 60 years. Using a value for BUA $<60 \mathrm{~dB} / \mathrm{MHz}$, sensitivity of $78 \%$, specificity of $100 \%$ and positive predictive value of $100 \%$ were obtained. Using BUA $<64 \mathrm{~dB} / \mathrm{MHz}$, sensitivity of $100 \%$, specificity of $90 \%$ and positive predictive value of $90 \%$ were obtained.

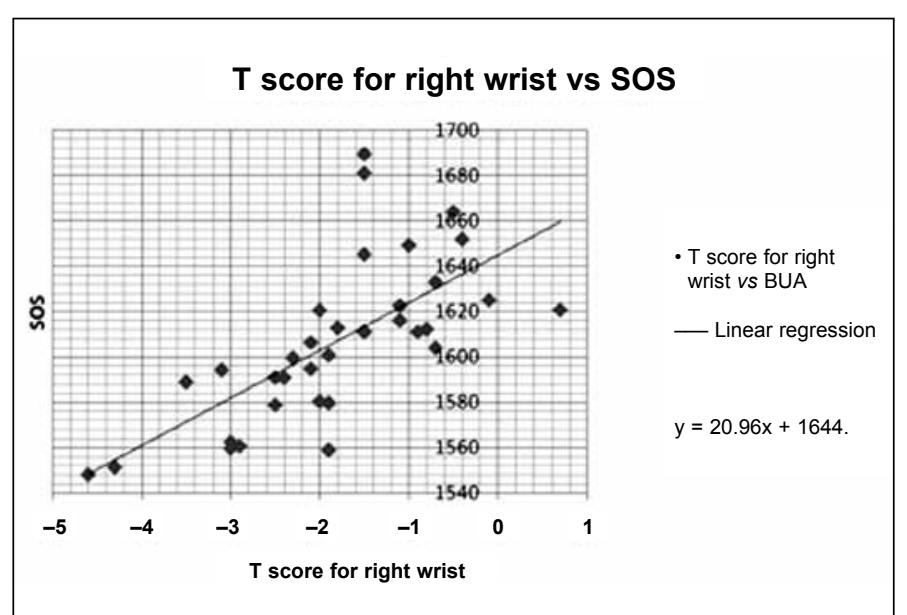

Figure 4 - Association between SOS and T score of the wrist for all the patients of the sample. Adopting a value for SOS of $1.592,5 \mathrm{~m} / \mathrm{s}$, sensitivity of $89 \%$, specificity of $85 \%$ and positive predictive value of $67 \%$ were obtained.

Table 1 - Sensitivity/specificity.

\begin{tabular}{c|c|c}
\hline DEXA site & BUA $<60$ & BUA $<64$ \\
\hline L1-L4 & $53 \% / 100 \%$ & $68 \% / 100 \%$ \\
\hline Total femur & $70 \% / 88 \%$ & $90 \% / 84 \%$ \\
\hline Neck of the femur & $73 \% / 92 \%$ & $82 \% / 83 \%$ \\
\hline Wrist & $77 \% / 100 \%$ & $92 \% / 95 \%$ \\
\hline
\end{tabular}

In Table 1, it is observed that when BUA $<64 \mathrm{~dB} /$ $\mathrm{MHz}$ is adopted as the cut-off point for predicting the risk of osteoporotic fracture, all the sensitivity values for all the sites compared were improved in all the patients. The best sensitivity was obtained in the wrists.
Table 2 - Sensitivity/specificity by age group (BUA < 64).

\begin{tabular}{c|c|c}
\hline DEXA site & $<60$ years & $\mathbf{6 0}$ or + \\
\hline L1-L4 & $38 \% / 100 \%$ & $91 \% / 100 \%$ \\
\hline Total femur & $67 \% / 92 \%$ & $100 \% / 75 \%$ \\
\hline Neck of the femur & $67 \% / 92 \%$ & $88 \% / 73 \%$ \\
\hline Wrist & $75 \% / 100 \%$ & $100 \% / 90 \%$ \\
\hline
\end{tabular}

In Table 2, the ultrasound was more sensitive, across all the comparison sites, for predicting the risk of osteoporotic fracture in patients aged 60 or over. The best sensitivity was obtained in the wrists.

Table 3 - Sensitivity/specificity.

\begin{tabular}{c|c}
\hline DEXA site & SOS $<\mathbf{1 5 9 2 . 5}$ \\
\hline L1-L4 & $84 \% / 100 \%$ \\
\hline Total femur & $64 \% / 79 \%$ \\
\hline Neck of the femur & $80 \% / 84 \%$ \\
\hline Wrist & $89 \% / 85 \%$ \\
\hline
\end{tabular}

In Table 3, the best sensitivity, using SOS to predict the risk of osteoporotic fracture, was in the wrists.

In all the correlations established, Pearson's coefficient correlation was 0.66 , demonstrating good correlation. Also, the confidence coefficient ( $p$ ) calculated was less than 0.001 , demonstrating that there is statistical significance in the data analyzed.

\section{DISCUSSION}

Ultrasound is being used for bone evaluation in the past few years and there are still doubts as to the accuracy of this method. Various studies show that its variables - SOS and BUA - reflect the bone density and other properties, such as elasticity and microarchitecture $^{(12)}$.

In a study carried out by Funke et al. ${ }^{(8)}$, in which 400 patients with fractures of the lumbar spine and neck of the femur were evaluated, including men and women, a good rate of correlation was obtained for the lumbar spine (Pearson's $r=0.49$ ) and neck of the femur (Pearson's $r=0.52$ ). Sensitivity and specificity of $85 \%$ were also observed for patients with osteoporotic fractures, using BUA $<64 \mathrm{~dB} / \mathrm{MHz}$ as the cut-off point. 
This work is unique in that it evaluates exclusively women with fractures of the wrist or lumbar spine. The same cut-off point was used (BUA $<64 \mathrm{~dB} / \mathrm{MHz}$ ) obtaining a Pearson's correlation coefficient of 0.66 . Sensitivity of $100 \%$ and specificity of $90 \%$ in the wrist site (not evaluated by Funke et al) in women aged over 60 is also observed in this work.

Sim et $\mathrm{al}^{(13)}$ analyzed 46 women aged between 50 and 80 years (mean age 65) submitted to ultrasound and DEXA of the lumbar spine and hip. The authors report that using BUA $<60 \mathrm{~dB} / \mathrm{MHz}$ as the cut-off point they obtained sensitivity of $93 \%$ and specificity of $84 \%$.

We calculated the value of SOS by the linear regression equation (DEXA vs. SOS) and found SOS $<$ $1592,5 \mathrm{~m} / \mathrm{s}$ as the cut-off point, with which we found sensitivity of $89 \%$ and specificity of $85 \%$. Langton et $\mathrm{al}^{(14)}$ evaluated 107 women aged between 60 and 69 (mean age 64), obtaining sensitivity of $54 \%$ and specificity of $70 \%$ using SOS $<1590 \mathrm{~m} / \mathrm{s}$. In a study by Falgarone et $\mathrm{al}^{(15)}$, 106 women with a mean age of 65 years were evaluated using $\mathrm{SOS}<1551,5 \mathrm{~m} / \mathrm{s}$, with sensitivity of $90 \%$ and specificity of $30 \%$ while for SOS $<1544,8 \mathrm{~m} / \mathrm{s}$, the values for sensitivity and specificity were $90 \%$ and $41 \%$, respectively.

\section{CONCLUSION}

Ultrasound of the calcaneus can be used as a screening method for risk of fracture due to osteoporosis, with sensitivity and specificity of over $80 \%$, when performed in patients with more than 60 years, using BUA $<64 \mathrm{~dB} / \mathrm{MHz}$ or $\mathrm{SOS}<1592,5 \mathrm{~m} / \mathrm{s}$ as the cut-off point.

Future works based on a larger cohort are needed to confirm these findings, and different age groups and populations should also be considered.

\section{REFERENCES}

1. WHO study group on Assessment of fracture risk and its application to screening for post menopausal osteoporosis: report of WHO. Geneva: World Health Organization; 1994. (WHO Technical report series; 843).

2. Oliveira LG, Milhomem DM, Namba E, Anjos LC, Aires RC, Irineu VM, et al. Screening ultrasonométrico do calcâneo em mulheres peri e pós-menopausadas em Goiânia GO. Rev Bras Doenças Osteometab, 2006;1(1):16-9.

3. McClung MR, Geusens P, Miller PD, Zippel H, Bensen WG, Roux C, et al. Effect of risedronate on the risk of hip fracture in elderly women. Hip Intervention Program Study Group. N Engl J Med. 2001;344(5):333-40.

4. Ettinger B, Black DM, Mitlak BH, Knickerbocker RK, Nickelsen T, Genant HK, et al. Reduction of vertebral fracture risk in postmenopausal women with osteoporosis treated with raloxifene: results from a 3-year randomized clinical trial. Multiple Outcomes of Raloxifene Evaluation (MORE) Investigators. JAMA. 1999;282(7):637-45.

5. Delmas PD, Ensrud KE, Adachi JD, Harper KD, Sarkar S, Gennari C, et al. Efficacy of raloxifene on vertebral fracture risk reduction in postmenopausal women with osteoporosis: four-year results from a randomized clinical trial. J Clin Endocrinol Metab. 2002;87(8):3609-17.

6. Neer RM, Arnaud CD, Zanchetta JR, Prince R, Gaich GA, Reginster JY, et al. Effect of parathyroid hormone (1-34) on fractures and bone mineral density in postmenopausal women with osteoporosis. N Engl J Med. 2001;344(19):1434-41.

7.Bauer DC, Glüer CC, Cauley JA, Vogt TM, Ensrud KE, Gennant HK, et al. Broadband ultrasound attenuation predicts fractures strongly and independently of densitometry in older women. A prospective study. Study of Osteoporotic Fractures Research Group. Arch Intern Med. 1997;157(6):629-634.

8. Funke M, Kopka L, Vosshenrich R, Fischer U, Ueberschaer A, Oestmann JW, et al. Broadband ultrasound attenuation in the diagnosis of osteoporosis: correlation with osteodensitometry and fracture. Radiology. 1995;194(1):77-81.

9. Pluijim SM, Graafmans WC, Bouter LM, Lips P. Ultrasound measurements for the prediction of osteoporosis fractures in elderly people. Osteoporosis. Int. 1999;9(6):550-6.

10. Khaw KT, Reeve J, Luben R, Bingham S, Welch A, Wareham N, et al. Prediction of total and hip fracture risk in men and women by quantitative ultrasound of the calcaneous: EPIC-Norfolk prospective population study. Lancet. 2004;363(9404):197-202.

11. Marín F, López-Bastida J, Díez-Pérez A, Sacristán JA. Bone mineral density referral for dual-energy $\mathrm{X}$-ray absorptiometry using quantitative ultrasound as a prescreening tool in postmenopausal women from the general population: a cost-effectiveness analysis. Calcif Tissue Int. 2004;74(3):277-83.

12. Cepollaro C, Gonnelli S, Pondrelli C, Martini S, Montagnani A, Rossi S, et al. The combined use of ultrasound and densitometry in the prediction of vertebral fracture. Br J Radiol. 1997;70(835):691-696.

13. Sim MF, Stone M, Johanser A, Evans W. Cost effectiveness analysis of BMD referral for DXA using ultrasound as a selective pre-screen in a group of women with low trauma Colles' fractures. Technol Health Care. 2000;8(5):277-84.

14. Langton CM, Ballard PA, Langton DK, Purdie DW. Maximising the cost effectiveness of BMD referral for DXA using ultrasound as a selective population pre-screen. Technol Health Care. 1997;5(3):235-41.

15. Falgarone G, Porcher R, Duche' A, Kolta S, Dougados M, Roux C. Discrimination of osteoporotic patients with quantitative ultrasound using imaging or non-imaging device. Joint Bone Spine. 2004;71(5):419-23. 